\title{
Intervention program for early readers: The teething problems
}

\begin{abstract}
The greatest challenge faced by schools is how to deal with at risk pupils especially those who are unable to read. Hence Reading Recovery Program that supplements daily reading and writing instructions seems to be the logical answer. In Malaysia an intervention program (KIA2M) was launched in 2006 to address the reading problems among Year 1 pupils. The specific aim is to enable these pupils to acquire the basic reading and writing skills. A preliminary qualitative study was carried out on four schools in Kuala Lumpur and Selangor to examine the progress and implementation of the program, Fourteen teachers from these schools were interviewed. Their responses were recorded and transcribed. Like any new program, the findings reveal that there are several teething problems. Among them are: 1 . Lack of trained teachers assigned to the program. 2. Courses for diagnosis of children are not carried out. 3. Lack of support and cooperation from teachers and parents. 3. Pupil -teacher ratio is not realistic. More than 30 pupils per teacher. 4. There is no follow up programs after the pupils have gone through Year 1. 5. Literacy is not the focus. Pupils are taught correct pronunciations, spelling and writing. 6. There is no networking with teachers from other schools and experts for the programs. Eleven of the teachers reported that the program has not fully achieved its aim. Suggestions for improvements from teachers' perspectives are discussed in this paper.
\end{abstract}

Keyword: Intervention Program, Early Readers, Teething Problems 